\title{
ASSIMILATIVE CAPACITY MODELING USING INTEGRATED WATERSHED AND LAKE MODELS IN SUPPORT OF THE GEORGIA COMPREHENSIVE STATEWIDE WATER MANAGEMENT PLAN
}

\author{
B.J. WATSON ${ }^{1}$, J. WYSS ${ }^{1}$, E.A. BOOTH ${ }^{2} \&$ G. SOUSA ${ }^{1}$ \\ ${ }^{1}$ Tetra Tech, Water Resources Group, Atlanta, Georgia, GA, USA. \\ ${ }^{2}$ Georgia Department of Natural Resources, Environmental Protection Division, \\ Watershed Protection Branch, Atlanta, Georgia, USA.
}

\begin{abstract}
In 2004, the Georgia State Legislature passed the Comprehensive Statewide Water Management Planning Act, which mandated the development of a statewide water plan. The vision of the Act was that Georgia manages its water resources in a sustainable manner to support the State's economy, to protect public health and natural systems, and to enhance the quality of life for all citizens. In 2008, the Georgia State Legislature adopted the Georgia Comprehensive Statewide Water Management Plan (State Water Plan), and provided funding for Resource Assessments, Forecasting, and Regional Water Planning. The purpose of Regional Water Plans is to guide each region in managing its water resources in a sustainable manner. This means not only allowing growth but also maintaining the ecological and biological health of the State's rivers, lakes, and estuaries, as well as protecting State water quality standards. To evaluate the State's water resources, the Georgia Environmental Protection Division (GAEPD), with the assistance of other agencies, conducted resource assessments to determine surface water availability, groundwater availability, and assimilative capacity. The assessments included the compilation and management of data, computer modeling of both current and future needs, and additional monitoring if needed. Results of the assessments were provided to Regional Planning Councils as a starting point for the development of a recommended Water Development and Conservation Plan. The Assimilative Capacity Resource Assessment included the development and calibration of a series of integrated models. Once calibrated, these models were used to evaluate a number of water management scenarios. These models are also being used to manage systems whose water quantity and quality are taxed and to assist in the development of nutrient criteria for various waterbody types. The approach taken by Georgia will serve as guide to other agencies in long-term water planning and sustainability.
\end{abstract}

Keywords: Assimilative capacity, lake, lake sustainability, lake water quality standards, modeling, nutrient criteria, reservoir, water quality, watershed.

\section{INTRODUCTION}

In support of the Georgia Comprehensive Statewide Water Management Plan (State Water Plan) [1], the Assimilative Capacity Resource Assessment was used to determine the capacity of Georgia's surface waters to absorb pollutants without unacceptable degradation of water quality. Assimilative capacity is defined as the amount of contaminant load that can be discharged to a specific waterbody without exceeding water quality standards or criteria. In other words, the assimilative capacity is used to define the ability of a waterbody to naturally absorb and use a discharged substance without impairing the water quality, without harming the aquatic life, or having the waterbody not meet its designated use. The Assimilative Capacity Resource Assessment included developing water quality models of selected streams, rivers, lakes, and estuaries throughout the State of Georgia. Evaluation of the assimilative capacity results focused on dissolved oxygen, nutrients (nitrogen and phosphorus), and chlorophyll- $a$. Water quality models were used to assess the impacts of municipal and industrial discharges, water withdrawals, land use, and meteorological conditions on the waterbody. In addition, the water quality models were used to assess a variety of scenarios that included, but were not limited 


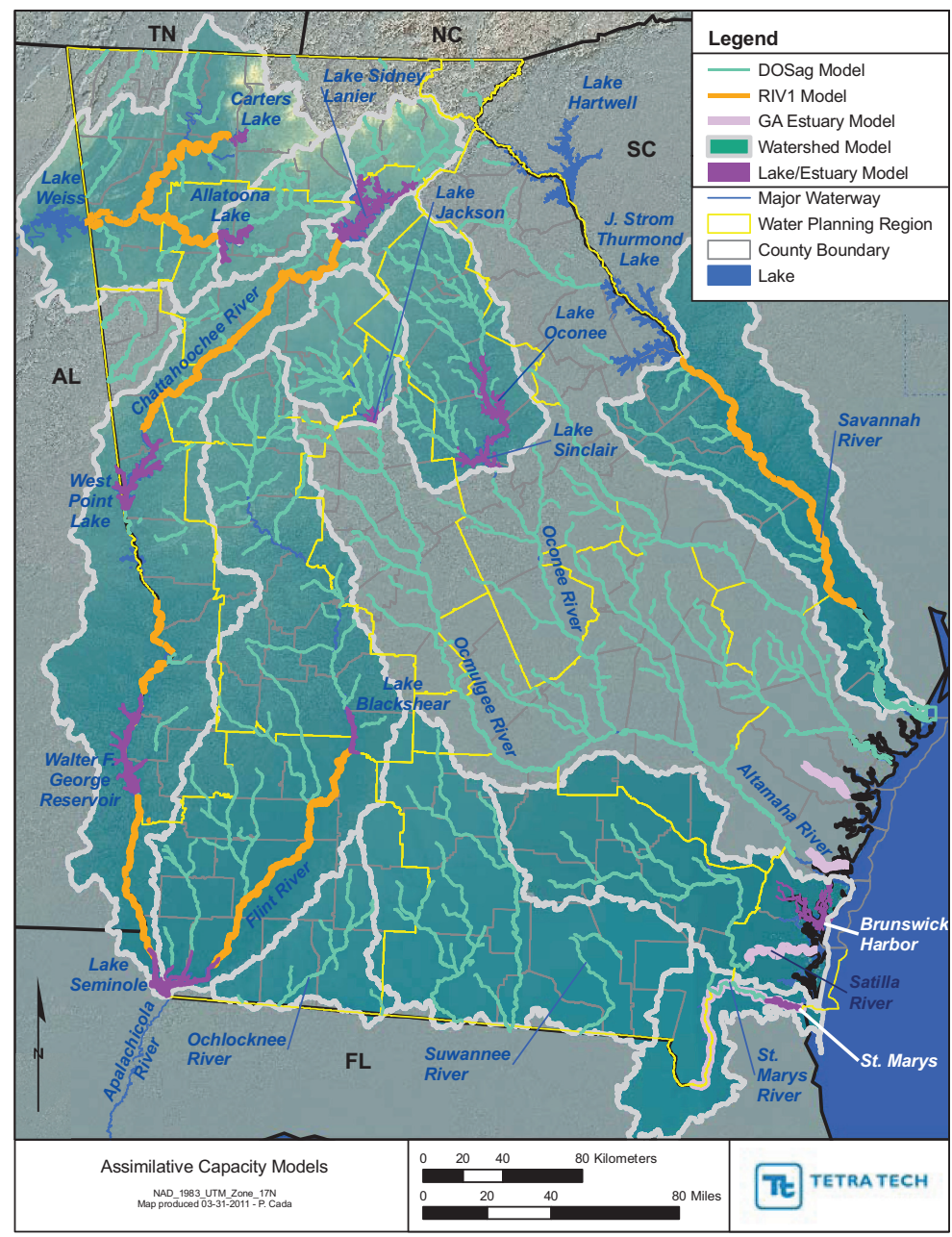

Figure 1: Assimilative capacity models for the GA State water plan.

to, future discharges and withdrawals, future land use, non-point source management practices, evaluation and development of stream and lake nutrient criteria, and lake/reservoir operational changes. The water quality models that have been developed and used to evaluate the assimilative capacity are shown in Fig. 1. This includes stream, river, watershed, lake, and estuary models.

For the State Water Plan, currently 10 lakes have been or are being modeled. They include Lakes: Lanier, West Point, Walter F. George, Seminole, Blackshear, Jackson, Oconee, Sinclair, Allatoona, and Carters. Water quality standards have been developed for six of these lakes, while standards will be developed for the other four. One of these lakes, Oconee, will be utilized as a case study in this paper.

\section{MODELS USED}

For the Assimilative Capacity Resource Assessment, five different models were utilized, but the focus herein will only be on two of them. The watershed model utilized was the Loading Simulation Program C++ (LSPC) [4] and the lake model was the Environmental Fluid Dynamics Code (EFDC) [2,3]. Both 
LSPC and EFDC have been extensively used and are part of the United States Environmental Protection Agency's (EPA) Total Maximum Daily Load (TMDL) Modeling Toolbox [5].

\subsection{Loading Simulation Program C++}

LSPC is a comprehensive data management and modeling system that is capable of representing loading, both flow and water quality, from non-point and point sources, and of simulating in-stream processes. It is capable of simulating flow, sediment, metals, nutrients, pesticides, and other conventional pollutants, as well as temperature and $\mathrm{pH}$ for pervious and impervious lands and waterbodies. LSPC represents the hydrological and water quality conditions in the watersheds and is configured to simulate the watershed as a series of hydrologically connected subwatersheds.

\subsection{Environmental Fluid Dynamics Code}

EFDC is a hydrodynamic and water quality modeling package for simulating one-dimensional, twodimensional, and three-dimensional flow and transport in surface water systems, including: rivers, lakes, estuaries, reservoirs, wetlands, and near-shore coastal regions. The EFDC model was originally developed for estuarine and coastal applications and is public domain software. EFDC was used to model the three-dimensional hydrodynamics and water quality of the lakes.

\subsection{Model Calibration and Validation}

Each model went through a rigorous calibration and validation process. Calibration of each model was performed by adjusting model parameters, within reasonable constraints, until an acceptable agreement was achieved between simulated and measured flow and water quality data. The model parameters were adjusted based on local knowledge, previous experience, literature data, and best professional judgment. Model validation is the process of taking the model parameters that have been calibrated, applying those parameters to other areas or time periods, and comparing the simulated and measured flow and water quality data. Model validation is sometimes called model verification, as essentially the modeler is validating or verifying that model parameters calibrated in one model will produce acceptable results in another area or time period.

The measured data used in the calibration and validation process were collected from various sources including, but were not limited to, United States Geological Survey (USGS) flow gages, point source discharge monitoring reports (DMRs), water withdrawal volumes, GAEPD water quality sampling stations (stream, river, and lake), the National Climate Data Center (NCDC), Georgia Automated Environmental Monitoring Network (GAEMN), and local watershed studies. Additional spatial datasets, such as land application systems, septic systems, and agricultural irrigation areas, were also included in the calibration process.

The simulation period for the LSPC and EFDC models was 7 years, from January 1, 2001 through December 31, 2007. This period was chosen as it overlaps the data collection efforts by GAEPD that occur monthly in each lake during the growing season (April through October).

\section{LAKE WATER QUALITY STANDARDS}

The 1992 Georgia Lake Law required the lake standards to be set that include a growing season average for chlorophyll- $a$, annual total phosphorus loads for the major tributaries, total lake phosphorus loading, and a total nitrogen limit for the lake. In addition, the law required standards be set for DO, temperature, $\mathrm{pH}$, and fecal coliform. For this assessment, only 
chlorophyll- $a$ and nutrient standards were examined. The associated water quality standards for these lakes can be found in Georgia's Rules and Regulations for Water Quality Control, Chapter 391-3-6-.03(17).

Of the 10 lakes that have been or are currently being modeled for the State Water Plan, six have lake standards: Lanier, West Point, Walter F. George, Jackson, Allatoona, and Carters. The standards developed for these lakes were used as a reference, when evaluating nutrient loadings and impacts to the remaining four lakes without standards.

\section{MODELING SCENARIOS}

A number of scenarios were evaluated for the State Water Plan [6]. Each scenario was assessed to determine whether the nutrient loadings from the combination of point source and non-point sources were impacting water quality and thereby affecting the assimilative capacity. For waterbodies where water quality standards existed, this process consisted of comparing model output directly to the appropriate standard. For waterbodies without standards, water quality outputs were compared against the other scenarios. Some of the scenarios that were evaluated are described below.

\subsection{Baseline Scenario}

The Baseline Scenario represents results produced from the calibrated models.

\subsection{Baseline Scenario with NPDES facilities removed}

This scenario was the Baseline Scenario with all National Pollution Discharge Elimination System (NPDES) facilities and water withdrawals removed. Results from this scenario provide information on how land use alone impacts water quality.

\subsection{Current Permit Scenario}

This scenario represents the Baseline Scenario with all NPDES facilities and water withdrawals input at their current permitted values of flow and water quality. For water quality parameters that did not have permit values, concentrations were assumed and assigned with conservative values.

\subsection{Current Permit Scenario with 2050 land use}

This scenario represents the Current Permit Scenario in the year 2050. This scenario assumes no increased loading for the NPDES facilities and water withdrawals but that the land use represents projected 2050 changes.

\subsection{Scenario}

The 2050 Scenario represents results produced using inputs that are projected for the year 2050 . Inputs projected for 2050 included land use, point source discharges, water withdrawals, septic systems, and land application systems. Meteorological input data were not projected and were not changed from the Baseline Scenario. 


\subsection{Scenario with NPDES facilities removed}

This scenario represents the 2050 Scenario with all NPDES facilities and water withdrawals removed. Similar to the Baseline Scenario with NPDES facilities removed, results from this scenario provide information on how the projected 2050 land use alone impacts water quality.

\subsection{Non-point source management practices scenarios}

These scenarios consisted of assuming a combination of non-point source management practices that would be applied either to a portion of the watershed or throughout the watershed. These practices contained low- and high-level Best Management Practices (BMPs) that were applied to urban, agricultural, and forest land uses. Low- and high-level BMPs were defined as a single BMP or a series of BMPs that had increasing nutrient removal rates. Three of the most common non-point source management practice scenarios that were evaluated were:

- Current Permit Scenario with 2050 land use with low-level BMPs

- 2050 Scenario with low-level BMPs

- 2050 Scenario with high-level BMPs

\section{LAKE OCONEE CASE STUDY}

Lake Oconee is within the Upper Oconee (8-digit HUC 03070101) watershed in central Georgia, approximately $121 \mathrm{~km}(75 \mathrm{mi})$ southeast of the city of Atlanta. Lake Oconee receives the majority of its inflow from the Oconee and Apalachee rivers. It discharges directly to Lake Sinclair through Wallace Dam. Wallace Dam is used to generate hydroelectric power and the two lakes are operated via pumpback from Lake Sinclair to Lake Oconee for that purpose. Wallace Dam was completed in 1980 and impounds water from a 4,422 $\mathrm{km}^{2}\left(1,707 \mathrm{mi}^{2}\right)$ drainage area. A total of 17 counties and the city of Athens, Georgia, home of the University of Georgia, are located either completely or partially in the Upper Oconee Watershed, thus making the watershed very important to a wide range of communities. For Lake Oconee, LSPC was used for the Upper Oconee Watershed model and EFDC was used for the Lake Oconee model [6,7].

\subsection{Integration of LSPC with EFDC}

For the Assimilative Capacity Resource Assessment, the Upper Oconee Watershed LSPC was successfully integrated with Lake Oconee EFDC model. The LSPC model provided flows, temperatures, and water quality concentrations to EFDC model from tributaries and adjacent watersheds. Figure 2 shows how the two models were integrated with one another and what output each model provided.

\subsection{Results for Lake Oconee}

After each scenario was performed, the simulated model output was processed and evaluated. The LSPC watershed models were analyzed for in-stream nutrient concentrations (both total phosphorus and total nitrogen) and in-stream nutrient loading. The EFDC lake models were analyzed for the growing season average chlorophyll- $a$ concentration (in $\mathrm{ug} / \mathrm{L}$ ), maximum total nitrogen concentration $(\mathrm{mg} / \mathrm{L})$ in the photic zone, and annual nutrient loading per annual lake volume (kilograms of total phosphorus/cubic meters of lake volume). By assessing these and other results, determinations 


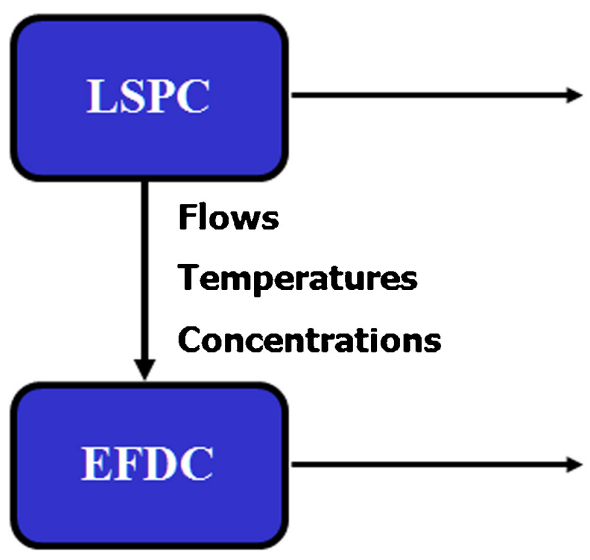

Subwatershed Flows

Subwatershed Concentrations (Chl-a, TN, NH3, NOx, OrgN, TP, P04, OrgP, BOD, DO, Temp, TSS, Fecal)

\section{Water Surface Elevations}

Profile Data

(Temperature and Dissolved Oxygen)

\section{Lake Concentrations}

(Chl-a, TN, NH3, NOx, OrgN, TP, PO4, OrgP, BOD, DO, Temp)

Figure 2: Integration of the Upper Oconee LSPC model with the Lake Oconee EFDC model.

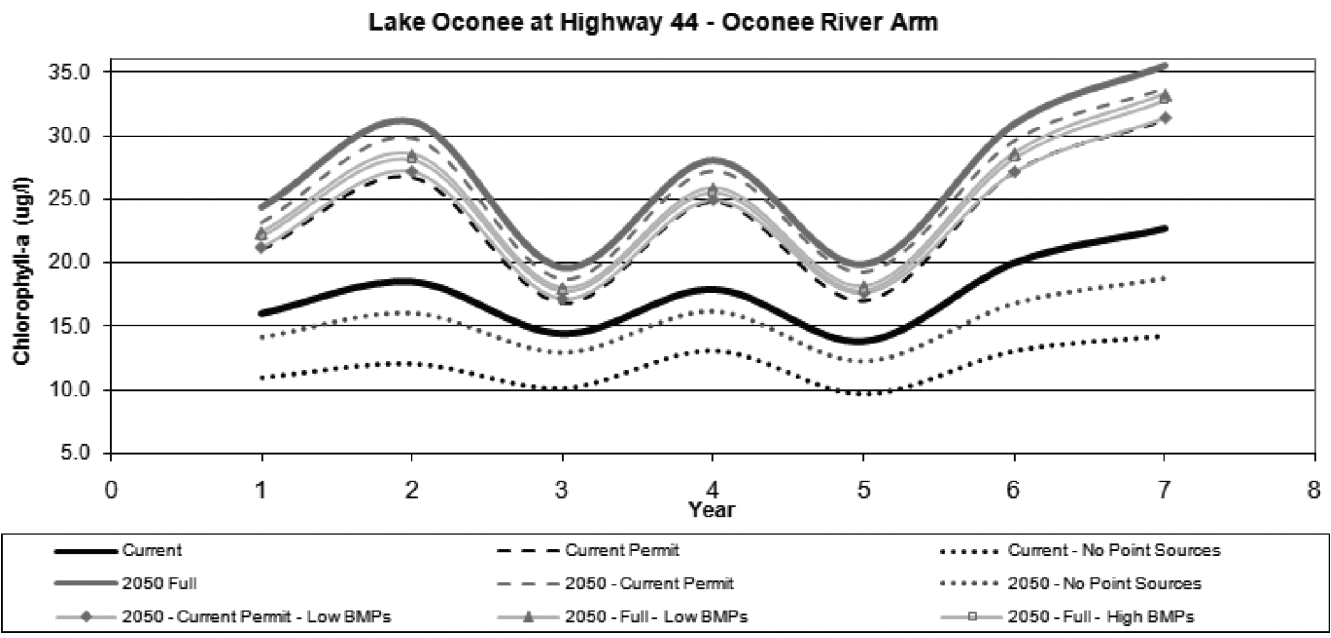

Figure 3: Results for Lake Oconee - Oconee River Arm.

were made about the overall water quality of the waterbody. Sample results for Lake Oconee are presented in the following sections.

\subsubsection{Chlorophyll- $a$}

Chlorophyll- $a$ is a primary indicator of a lake's overall ecological and biological health. GAEPD assesses lake chlorophyll- $a$ values by averaging monthly samples taken during the growing season, April through October. Growing season chlorophyll- $a$ average values were evaluated at several points throughout the lake. In Lake Oconee, the growing season chlorophyll- $a$ average values were assessed at two primary tributaries coming into the lake, Oconee River and Richland Creek, and at the Dam Forebay. Figures 3 through 5 present 7 years of the results at the respective locations. 


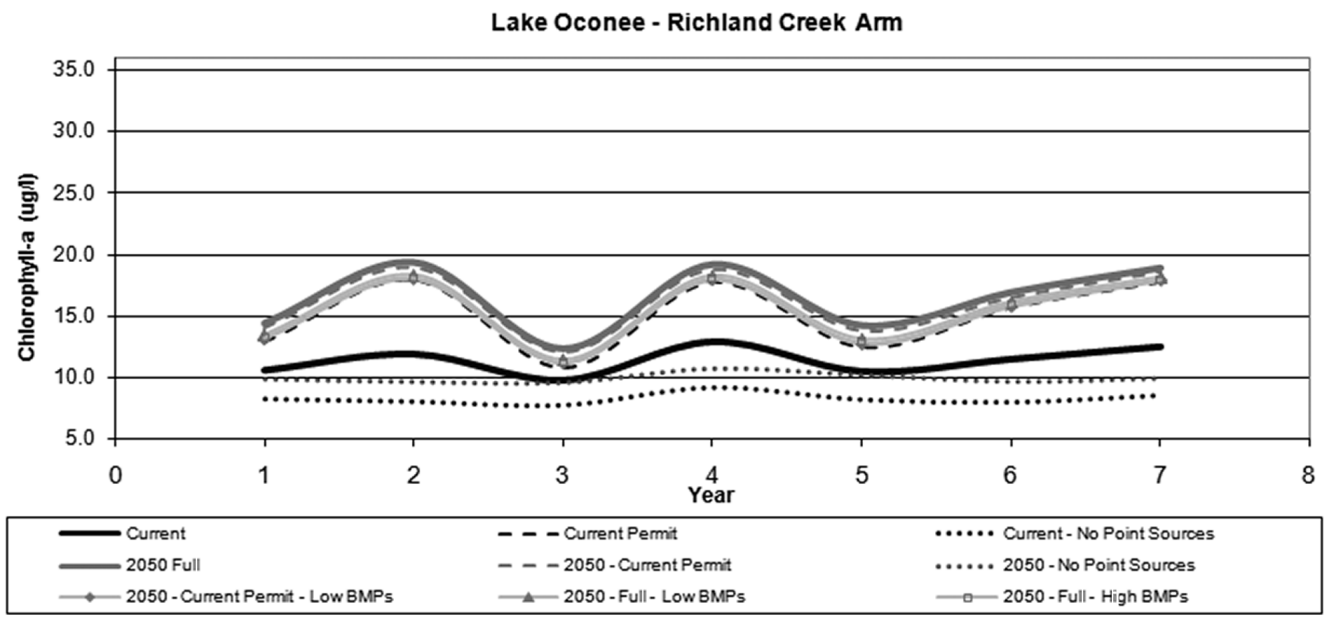

Figure 4: Results for Lake Oconee - Richland Creek Arm.

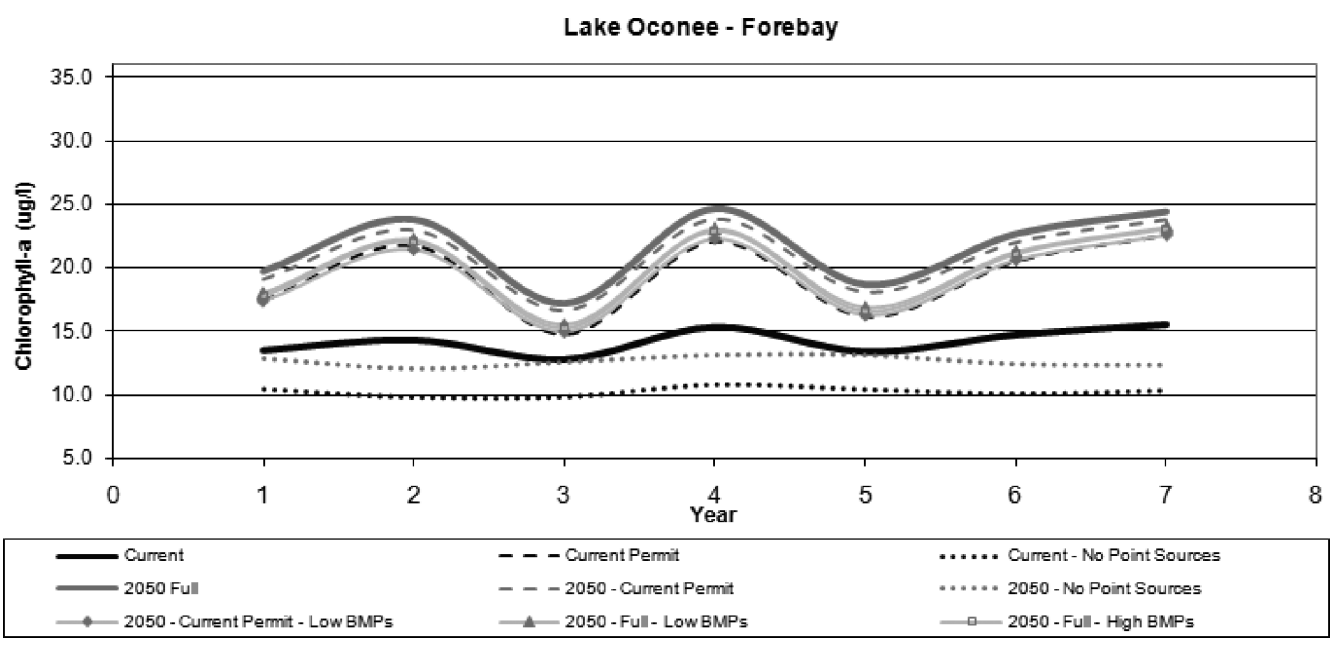

Figure 5: Results for Lake Oconee - Dam Forebay.

\subsubsection{Total Nitrogen}

The maximum total nitrogen concentration was assessed for each lake. This assessment was done for both wet years and dry years to evaluate the different tributary loading conditions and the associated impact to water quality within the lake. Figures 6 and 7 present the maximum total nitrogen concentration in Lake Oconee for a representative wet year and dry year, respectively.

\subsubsection{Annual phosphorus loading per annual lake volume}

The annual phosphorus loading per annual lake volume was determined by summing the total annual phosphorus loading determined from the LSPC watershed model and dividing by the total annual 


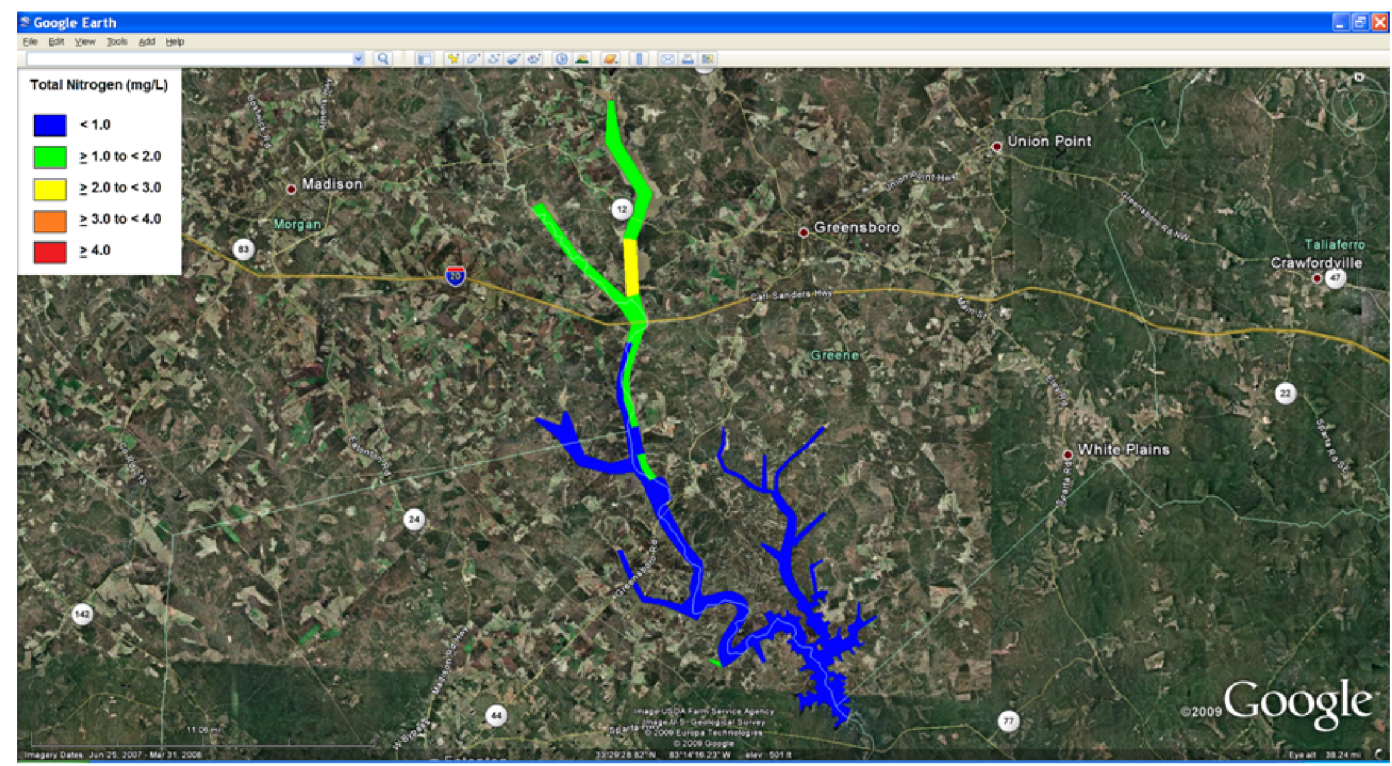

Figure 6: Representative total nitrogen concentration in Lake Oconee during a wet year.

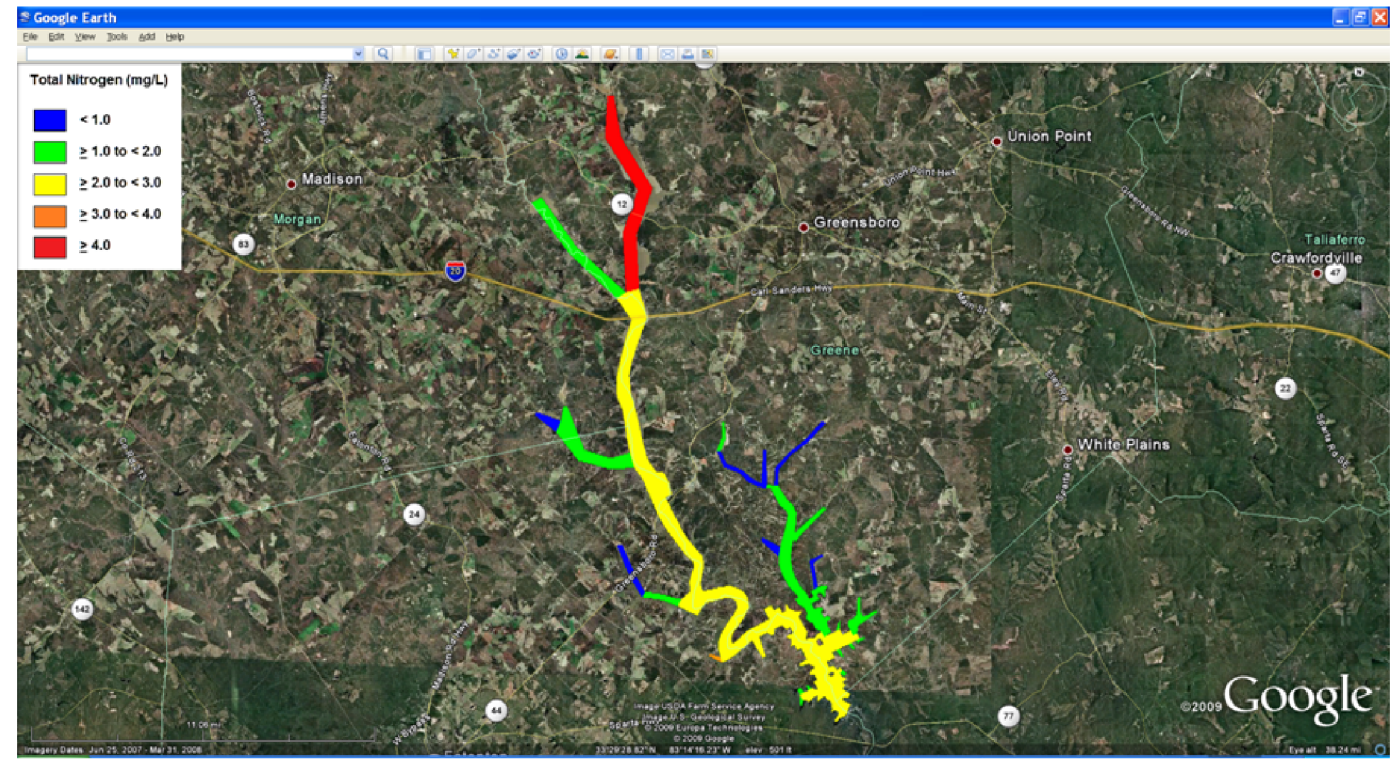

Figure 7: Representative total nitrogen concentration in Lake Oconee during a dry year.

lake volume. Table 1 presents the annual total phosphorus loading per annual lake volume for the scenarios evaluated. Depending on the scenario, the annual total phosphorus loading changed, so the results in Table 1 show the values of both the total annual phosphorus loading and the associated annual nutrient loading per annual lake volume. 


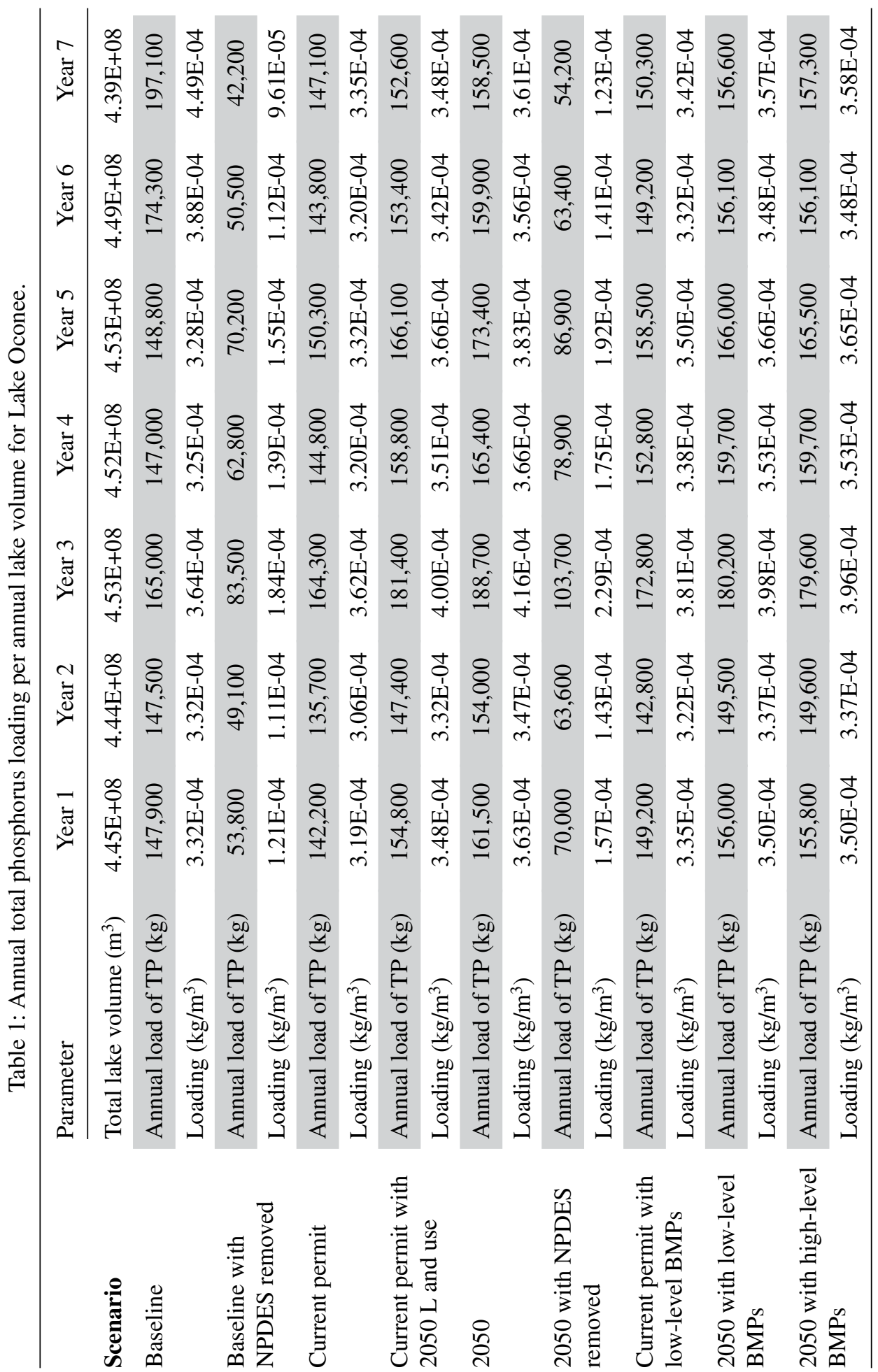




\subsection{Summary of results}

In analyzing Lake Oconee, where lake water quality standards do not exist, the LSPC and EFDC models will be utilized to establish targets and ultimately standards that will protect the aquatic life and the lake's designated use. For example, growing season average chlorophyll- $a$ concentration standards established at the six lakes ranges from 5 to $27 \mathrm{ug} / \mathrm{L}$. The Baseline Scenario for Lake Oconee ranges from 13 to $23 \mathrm{ug} / \mathrm{L}$ and the 2050 Scenario ranges between 17 and $36 \mathrm{ug} / \mathrm{L}$, lakes with total nitrogen concentration standards range from 3 to $4 \mathrm{mg} / \mathrm{L}$, which is a standard that is applied year-round to every station. There are several years where Lake Oconee exceeds $4 \mathrm{mg} / \mathrm{L}$. The annual phosphorus loading per annual lake volume standard ranges from 9.2 to $0.02 \times 10^{-5} \mathrm{~kg} / \mathrm{m}^{3}$, where Lake Oconee ranges from 9.6 to $0.45 \times 10^{-5} \mathrm{~kg} / \mathrm{m}^{3}$. With knowledge that Lake Oconee is currently experiencing algal blooms, model results show exceedance of the other lake standards, and the need for lake sustainability, it is likely that GAEPD will establish water quality standards for Lake Oconee that will require a reduction in overall nutrient loading and the integrated LSPC watershed and EFDC lake models will become imperative for this task.

\section{CONCLUSIONS}

Models developed for the State Water Plan are being utilized for several purposes. Scenarios were evaluated to provide results to the Regional Planning Councils, who used the results to develop Regional Water Plans [8]. The models are also being used to develop TMDLs, for wasteload allocations, for numeric nutrient standards, and to make other water management decisions.

A critical component of the water quality models is the successful integration of the LSPC watershed model to the EFDC lake model. This integration allows a more precise estimate of the nutrient loadings to the receiving waterbody, particularly when data are limited. In addition, if nutrient loadings to the lake show exceedance of water quality standards or water quality targets (if standards do not exist), then the integrated watershed and lake models can be used to examine the effects that point and/or non-point source reductions in watershed nutrient loadings will have on the lake.

As our water quantity and quality resources become more taxed, the approach taken by GAEPD with the State Water Plan will serve as a guide to other agencies in long-term water planning and sustainability.

\section{ACKNOWLEDGEMENTS}

Tetra Tech and the Georgia Environmental Protection Division successfully collaborated in the development of the various models, analyses of results, staff support, and in the preparation of numerous documents. Without this combined team effort, which included over 50 personnel, this project could not have been completed.

\section{REFERENCES}

[1] GAEPD, Georgia Comprehensive State-wide Water Management Plan, www.georgiawaterplanning.org, 2008.

[2] Hamrick, J.M. A Three-Dimensional Environmental Fluid Dynamics Computer Code: theoretical and computational aspects. The College of William and Mary, Virginia Institute of Marine Science, Special Report, 317, p. 63, 1992.

[3] Hamrick, J.M. Linking hydrodynamic and biogeochemical transport models for estuarine and coastal waters. Estuarine and Coastal Modeling, Proceedings of the 3rd International Conference, eds. M.L. Spaulding et al, American Society of Civil Engineers, New York, pp. 591-608, 1994. 
[4] Tetra Tech, Loading Simulation Program C++ (LSPC) Version 3.1 User's Manual. Tetra Tech, Fairfax, Virginia. http://www.epa.gov/athens/wwqtsc/html/lspc.html

[5] USEPA, (http://www.epa.gov/athens/wwqtsc/). Selected Deliverable Reports produced under the Assimilative Capacity Water Quality Modeling and Water Quality Standards Review contract as part of the Georgia Comprehensive State-wide Water Management Plan.

[6] Tetra Tech, Watershed Hydrology and Water Quality Modeling Report for the Upper Oconee Watershed, Georgia - REV1. Tetra Tech, Atlanta, Georgia, 2009a.

[7] Tetra Tech, Hydrodynamic and Water Quality Modeling Report for Lake Oconee and Lake Sinclair, Georgia - REV0. Tetra Tech, Atlanta, Georgia, 2009b.

[8] Tetra Tech, Assimilative Capacity Resource Assessment Scenario Report In Support of the Georgia Comprehensive State-wide Water Management Plan. Tetra Tech, Atlanta, Georgia, 2011. 